\title{
CURCUMIN AND ITS NANOFORMULATIONS: A COMPREHENSIVE OVERVIEW FOR THE MANAGEMENT OF DIABETES COMPLICATIONS
}

\author{
JUNMONI NATH*, BHUPEN KALITA, GOURANGA DAS \\ Department of Pharmaceutics, Girijananda Chowdhury Institute of Pharmaceutical Sciences, Azara, Guwahati 781017 \\ Email: junmoninath2014@gmail.com
}

Received: 14 Apr 2019, Revised and Accepted: 13 Jun 2019

\begin{abstract}
Diabetes is a chronic metabolic disorder that has reached pandemic proportions, and which is a major cause of morbidity and mortality worldwide. Type 1 diabetes is an autoimmune disorder resulting in almost complete destruction (98\%) of insulin secreting beta cells in the pancreas, while type 2 diabetes is considered to be a disease of protein misfolding where, in addition to the average $65 \%$ loss of beta cell mass, insulin resistance occurs in target organs. Diabetic complications, such as retinopathy, nephropathy, neuropathy and cardiovascular disease, are common and majorly impact a patient's quality of life. Curcumin is the yellowish polyphenolic component of the dietary spice turmeric, which is the rhizomes of Curcuma longa, a herb in the ginger family (Zingiberaceae). Curcumin effectively reduces glycemia and hyperlipidemia but also has beneficial effects on diabetic complications due to its anti-inflammatory and antioxidant properties, in a relatively inexpensive and safe manner. New improved methods of delivering curcumin are being developed including nanoparticles and lipid/liposome formulations that increases its absorption and bioavailability as curcumin is poorly absorbed by the digestive system and undergoes glucuronidation and excretion rather than being released into the serum and systemically distributed. Development and refinement of these technologies will enable cell-directed targeting of curcumin and improved therapeutic outcome. The current review focuses on the antidiabetic efficacy of curcumin and nano-drug delivery approaches in attenuating diabetes and its complications.
\end{abstract}

Keywords: Curcumin, Diabetes, Nanoparticle, Liposomes

(C) 2019 The Authors. Published by Innovare Academic Sciences Pvt Ltd. This is an open access article under the CC BY license (http://creativecommons.org/licenses/by/4.0/] DOI: http://dx.doi.org/10.22159/ijcpr.2019v11i4.34932

\section{INTRODUCTION}

Diabetes, a metabolic disorder, has been categorized as Type 1 and Type 2. Type 1 diabetes is an autoimmune disorder resulting in almost complete destruction (98\%) of insulin secreting beta cells in the pancreas, while type 2 diabetes is considered to be a disease of protein misfolding where, in addition to the average $65 \%$ loss of beta cell mass, insulin resistance occurs in target organs [1].

Inflammatory cytokines, transcription factors and enzymes, oxidative stress, intracellular sorbitol and tissue advanced glycation end products (AGEs) accumulation, activation of protein kinase-c (PKC) polyol pathway and mitochondrial superoxide production all play a role in the development of diabetic complications [2]. Curcumin, the yellowish polyphenolic component of the dietary spice turmeric, which is the rhizomes of Curcuma longa, a herb in the ginger family, effectively reduces glycemia and hyperlipidemia but also has beneficial effects on diabetic complications due to its anti-inflammatory and antioxidant properties, in a relatively inexpensive and safe manner [3, 4]. Several studies have designated that curcuminhas pleiotropic effects and a wide spectrum of molecular targets that regulate several pathways, intracellular elements, and key enzymes $[5,6]$. However, the natural curcumin is linked with some major drawbacks such as poor absorption, low bioavailability, high metabolic rates and rapid excretion from the body. Notwithstanding a century of continuous research inventions and efforts have aimed to overcome the obstacles of native curcumin, the invasion of nanoparticle formulations assimilated a definitivechange for treating a wide range of diseases utilizing nanocurcumin through efficient drug distribution process. The several studies report the development and in vitro evaluation of nanocurcumin that is proposed for site-specific delivery of curcumin with high permeability, lengthier circulation and improved biodistribution which brings major efficacious responses [7]. Thus, to enhance the same, various nanoparticle-based tactics have also been sought, such as encapsulation in liposomes, chitosan and solidlipid microparticles based technique utilizing bovine serum albumin to allocate the various impairments such as poor absorption rate, low bio-availability, and distribution, targeted delivery to the affected tissue of interest which limits its appropriate therapeutic effects [8-10]. This review seeks to briefly abridge the sufficient scientific literatures regarding curcumin as a potential treatment for diabetes and its associated complications.

\section{Methodology}

To formulate this review, all the available literature regarding to this topic was collected through electronic databases including Pubmed, Web of Science, Medline, Embase, Sciencedirect, Scopus, Cochrane Library, and Google Scholar.

\section{Curcumin and glycemia}

The effect of curcumin on glycemia has been studied by using several experimental models of diabetes. Oral administration of curcumin in several dosages [11-14] stopped weight loss, reduced glucose and glycated hemoglobin A1c (HbA1c) levels and enhanced insulin sensitivity, and hypoinsulinemia [15] in alloxan-induced diabetic rats, streptozotocin (STZ-) induced rats, and STZnicotinamide-induced rat models, all of which resemble Type $1 \mathrm{DM}$. Similarly, oral administration of curcumin enhanced glucose homeostasis and insulin resistance in rats with high-fat diet-induced Type 2 DM [16].

Curcumin reduces circulating free fatty acids (FFAs). FFA-induced lipotoxicity is ansignificant contributor of insulin resistance. This mechanism has been proposed to deteriorate pancreatic $\beta$-cell function [17] and impair the insulin signaling pathway through activation of NF-kb. Downstream products of the NF-kb pathway, such IL-6, interfere with the transcription of insulin receptors (such as insulin receptor substrate-1) and transporters (such as GLUT-4), thus impairing insulin sensitivity [18]. Finally, curcumin has been reported to induce peroxisome proliferator-activated receptor gamma activation [19].

\section{Curcumin and diabetic retinopathy}

Diabetic retinopathy (DR) is one of the most severe ocular sequelae due to chronic hyperglycemia. DR is the major cause of vision loss, affects the photoreceptors and blood vessels of the retina and is considered as one 
of the most devastating complications of diabetes. The factors that are thought to play a role in the development of DR are disturbances in retinal metabolism, elevatednonenzymatic glycation, oxidative stress, and Protein Kinase c (PKC) function [20, 21].

It has been reported that a novel curcumin-lecithin delivery form ( 2 tablets per day containing $100 \mathrm{mg}$ curcumin for $4 \mathrm{w}$ ), improved retinal flow, DME and visual acuity in diabetic patients [22]. It has been found that through positive modulation of the antioxidant redox system in the diabetic rats curcumin exhibits significant hypoglycemic effects., Retinal GSH levels and activity of antioxidant enzyme, superoxide dismutase(SOD) were attenuated after supplementation [23]. It also has been reported that the retinal antioxidant capacity can be restored by curcumin treatment, and also eradicates expression in the retina of proinflammatory cytokines, tumor necrosis factor (TNF- $\alpha$ ), vascular epithelial growth factor (VEGF) and Intercellular Adhesion Molecule-1(ICAM-1) in diabetic rats [23-27]. PKC $\beta$ II translocation can be inhibited by curcumin, which is induced through VEGF in human RECs [28]. Furthermost evidence supports the beneficial effect of curcumin treatment for DNA damage reduction through suppression of NF- $\mathrm{B}$ activation, and repositioning of oxidatively modified DNA and nitrotyrosinein the diabetic rat retina [29].

Curcumin has been reported to show shows antiapoptotic effect in the diabetic retina through high-expression of Bcl-2, down regulation of Bax and glutamine syntheta, mitigation of cell death in Müller cells, and a decrease in glial fibrillary acidic protein (GFAP) levels. Thus these findings suggests that curcumin could delay the beginning of apoptosis, a predictor of the DR formation, in retinal cells [30].

The formation of Cataract in STZ or the selenite rat model of diabetes can also be prevented by curcumin. Especially, curcumin down-regulates the main proteins (Heat Shock Protein 70, $\alpha \mathrm{A}$ crystalline, and $\alpha \mathrm{B}$-crystallin) involved in the protection of eye lens transparency and are overexpressed in cataracts [31-33]. Curcumin when delivered in the form of nanomicelle through nasal route was found to exert a beneficial effect on diabetic keratopathy and resulted in the promotion of corneal epithelial or nerve wound healing in STZ-induced diabetic mouse [34].

Curcumin is also helpful in early retinal vascular leakage, by suppression of Calcium/calmodulin-dependent protein kinase II (CaMKII)/NF- $\kappa$ B signaling in diabetic rat retina [35-37]. Diabetic patients are likely to develop corneal disorders, such as degeneration of nerve fibers, corneal neovascularization (CNV), corneal epithelial damage, corneal ulcers, reduced corneal sensitivity, reduced tear secretion and tear film [38, 39]. The most common cause of vision loss worldwide ia CNV. Curcumin has been found to ameliorates CNV formation through suppression of low density lipoprotein receptor-related protein 6 (LRP6) phosphorylation and $\beta$-catenin nuclear localization, two markers of the activated Wnt/ $\beta$-catenin pathway [40].

\section{Curcumin and diabetic neuropathy}

Diabetic neuropathy develops as a result of hyperglycemiainduced peripheral nerve damage [41]. The NF-kB transcription factor in peripheral neurons is activated due to Hyperglycemia induced oxidative stress. The NF-kB-mediated proinflammatory cytokines such as IL-6, TNF- $\alpha$, cyclooxygenase-2, and inducible nitric oxide synthase (iNOS) generation drives the neuroinflammatory-mediated nerve damage in peripheral neuropathy [42]. Depletion of endogenous antioxidants occurs due to the generation of High reactive nitrogen species/ROS. It has been found that tetrahydrocurcumin, a major metabolite of curcumin, by induction of antioxidant defenses, is able to inhibit the development of STZinduced diabetic nephropathy and neuropathy [43].

Curcumin is also reported to exhibit an anti-TNF- $\alpha$ activity and nicotinamide adenine dinucleotide phosphate oxidase inhibitory effect through which it ameliorates the sensorimotor disturbances associated with diabetic neuropathy [44]. Again, a grouping of gliclazide plus curcumin and insulin and curcumin, and have proved the high efficacy of combination treatments in preventing the STZ- induced alterations in sensory and motor functions compared with insulin or gliclazide monotherapy in diabetic rat models [45].

Curcumin supplement (60 mg/kg; p. o.) has been shown to significantly reduce cognitive impairment, dysfunctional cholinergic activity diabetic encephalopathy, neurodegeneration and neuroinflammation in diabetic rats [46]. Also it has been reported that curcumin supplement ameliorated the slowing nerve conduction and CNS dysfunction in diabetic rats [47-49].

\section{Curcumin and diabetic nephropathy}

Diabetic nephropathy (DN) is the most common cause of end stage renal failure $[50,51]$. Various mechanisms such as oxidative stress, renal hemodynamic changes, increased non-enzymatic glycosylation of proteins, lipid disorders, and the activation of the polyol and mitogen-activated protein kinase signaling pathways has been suggested to play a role in the development of diabetic nephropathy. Pathophysiological characteristics in the early stage of DN such as mesangial cell expansion, the accumulation of extracellular collagen, fibronectin, and laminin, glomerular and tubular membrane thickening, tubulointerstitial fibrosis, glomerulosclerosis, and finally renal endothelial dysfunction occurs in diabetic kidney disease [52].

Also, oral turmeric supplementation showed beneficial effects on glomerular function and inflammation in a clinical study performed on patients with overt Type 2 DM associated nephropathy. Moreover, curcumin $(100 \mathrm{mg} / \mathrm{kg} /$ day, p. o. $8 \mathrm{w})$ treatment downregulates the nicotinamide adenine dinucleotide phosphate (NADPH) oxidase subunits, NOX4 and p67phox, which are an underlying mechanism for boosting ROS production [53, 54]. Curcumin was found to mitigate nephropathy through the induction of antioxidant defenses and reduction of ROS mediated oxidative stress and the inflammatory cascade in kidneys regardless of the signaling pathway through which it acts. It was also reported to increase the function of kidney and integrity by reducing proteinuria and inhibiting leaching of renal enzymes and acid phosphatases [55].

\section{Nanoformulations of curcumin}

The major rate-limiting factor in allowing curcumin to exert its therapeutic effect is its poor oral bioavailability. Thus, various formulation strategies such as micronization, nanonization, amorphous solid dispersion, combination with piperine, complexation with hydroxypropyl-b cyclodextrin complex, and spraydried curcumin-milk composite have been tried to increasethe oral bioavailability of curcumin [56]. Of the many approaches, nanoparticle-based delivery systems will probably be suitable for highly hydrophobic agents like curcumin circumventing the pitfalls of poor aqueous solubility, however further investigations are needed to understand the ability of nanoparticles in delivering very high dose compounds such as curcumin. Use of polymeric nanoparticles has been actively explored as oral delivery vehicles for pharmaceutically challenging compounds $[57,58]$. The selfnanoemulsifying drug delivery system formulation of curcumin had higher physiological concentrations of curcumin and more improvement in sensorimotor nerve disturbances associated with diabetic neuropathy than naïve curcumin. It also reduced neuroinflammation associated with neuropathy by reducing the expression of proinflammatory mediators such as IL-6, TNF- $\alpha$, and iNOSthrough inhibition of NF-kB [48].

Also it has been reported that nanocurcumin (curcumin encapsulated PLGA nanoparticles) demonstrated a better performace in comparison with curcumin, as far as delay of cataract development is concerned, in four different ways: 1) by preventing protein carbonyl levels to rise 2) by normalizing AR activity (an enzyme playing a critical role in the polyol pathway) and subsequently reducing sorbitol levels 3 ) by reducing AGE formation in soluble protein fraction and 4) by improving the total and soluble protein levels, as protein in-solubilization is the final step to lens opacification and cataract [59].

\section{CONCLUSION}

Recent research has provided the scientific basis for "traditional" curcumin and confirmed the important role of curcumin in the 
prevention and treatment of diabetes and its associated disorders. Curcumin could favorably affect most of the leading aspects of diabetes, including insulin resistance, hyperglycemia, hyperlipidemia, and islet apoptosis and necrosis. In addition, curcumin could prevent the deleterious complications of diabetes. Despite the potential tremendous benefits of this multifaceted nature product, results from clinical trials of curcumin are only available in using curcumin to treat diabetic nephropathy, microangiopathy and retinopathy so far. Studies are badly needed to be done in humans to confirm the potential of curcumin in limitation of diabetes and other associated disorders. Further, multiple approaches are also needed to overcome limited solubility and poor bioavailability of curcumin. These include synthesis of curcuminoids and development of novel formulations of curcumin, such as nanoparticles, liposomal encapsulation, emulsions, and sustained released tablets. Enhanced bioavailability and convinced clinical trial results of curcumin are likely to bring this promising natural product to the forefront of therapeutic agents for diabetes by generating a "super curcumin" in the near future.

\section{AUTHORS CONTRIBUTIONS}

All the author have contributed equally

\section{CONFLICT OF INTERESTS}

Declare none

\section{REFERENCES}

1. Zaccardi F, Webb DR, Yates T, Davies MJ. Pathophysiology of type 1 and type 2 diabetes mellitus: a 90 -year perspective. Postgrad Med J 2016;92:63-9.

2. Moller D, Berger J. Role of PPARs in the regulation of obesityrelated insulin sensitivity and inflammation. Int J Obes 2003;27 Suppl 3:S17-21.

3. Goel A, Kunnumakkara AB, Aggarwal BB. Curcumin as 'curecumin': from kitchen to clinic. Biochem Pharmacol 2008; 75:787-809.

4. Chuengsamarn S, Rattanamongkolgul S, Luechapudiporn R, Phisalaphong C, Jirawatnotai S. Curcumin extract for prevention of type 2 diabetes. Diabetes Care 2012;35:2121-7.

5. Gururaj AE, Belakavadi M, Venkatesh DA, Marme D, Salimath BP. Molecular mechanisms of anti-angiogenic effect of curcumin. Biochem Biophys Res Commun 2002;4:934-42.

6. Karimian MS, Pirro M, Majeed M, Sahebkar A. Curcumin as a natural regulator of monocyte chemoattractant protein-1. Cytokine Growth Factor Rev 2017;33:55-63.

7. Sahni JK, Baboota S, Ali J. Promising role of nanopharmaceuticals in drug delivery. Pharm Times 2011;43:16-18.

8. Wang D, Veena MS, Stevenson K, Tang C, Ho B, Suh JD, et al. Liposome-encapsulated curcumin suppresses growth of head and neck squamous cell carcinoma in vitro and in xenografts through the inhibition of nuclear factor kappa B by an AKTindependent pathway. Clin Cancer Res 2008;14:6228-36.

9. Das RK, Kasoju N, Bora U. Encapsulation of curcumin in alginate-chitosan-pluronic composite nanoparticles for delivery to cancer cells. Nanomedicine 2010;6:153-60.

10. Gupta SK, Kumar B, Nag TC, Agrawal SS, Agrawal R, Agrawal P, et al. Curcumin prevents experimental diabetic retinopathy in rats through its hypoglycemic, antioxidant, and anti-inflammatory mechanisms. J Ocul Pharmacol Ther 2011;27:123-30.

11. Arun N, Nalini N. Efficacy of turmeric on blood sugar and polyol pathway in diabetic albino rats. Plant Foods Hum Nutr 2002;57:41-52.

12. Peeyush KT, Gireesh G, Jobin M, Paulose CS. Neuroprotective role of curcumin in the cerebellum of streptozotocin-induced diabetic rats. Life Sci 2009;85:704-10.

13. Zhang $\mathrm{YK}, \mathrm{Li} \mathrm{JM}, \mathrm{Qin} \mathrm{L}$. Suppression of corneal neovascularization by curcumin via inhibition of $\mathrm{Wnt} / \beta$ catenin pathway activation. Int J Ophthalmol 2017;10:1791.

14. Patumraj S, Wongeakin N, Sridulyakul P, Jariyapongskul A, Futrakul N, Bunnag S. Combined effects of curcumin and vitamin $\mathrm{C}$ to protect endothelial dysfunction in the iris tissue of STZ-induced diabetic rats. Clin Hemorheol Microcirc 2006; 35:481-9.
15. Shehzad A, Ha T, Subhan F, Lee YS. New mechanisms and the anti-inflammatory role of curcumin in obesity and obesityrelated metabolic diseases. Eur J Nutr 2011;50:151-61.

16. El-Moselhy MA, Taye A, Sharkawi SS, El-Sisi SF, Ahmed AF. The antihyperglycemic effect of curcumin in high fat diet fed rats. Role of TNF-a and free fatty acids. Food Chem Toxicol 2011;49:1129-40.

17. Shimabukuro M, Zhou YT, Levi M, Unger RH. Fatty acid-induced beta cell apoptosis: a link between obesity and diabetes. Proc Natl Acad Sci USA 1998;95:2498-502.

18. Liang H, Yin B, Zhang H, Zhang S, Zeng Q Wang J, et al. Blockade of tumor necrosis factor (TNF) receptor type 1-mediated TNFalpha signaling protected Wistar rats from diet-induced obesity and insulin resistance. Endocrinology 2008;149:2943-51.

19. Forbes JM, Cooper ME. Mechanisms of diabetic complications. Physiol Rev 2013;93:137-88.

20. Bril V. Treatments for diabetic neuropathy. J Peripher Nerv Syst 2012;17:22-27.

21. Baynes JW, Thorpe SR. Role of oxidative stress in diabetic complications: a new perspective on an old paradigm. Diabetes 1999;48:1-9.

22. Steigerwalt R, Nebbioso M, Appendino G, Belcaro G, Ciammaichella G, Cornelli U, et al. A lecithinized curcumin delivery system, in diabetic microangiopathy and retinopathy. Panminerva Med 2012;54:11.

23. Gupta SK, Kumar B, Nag TC, Agrawal SS, Agrawal R, Agrawal P, et al. Curcumin prevents experimental diabetic retinopathy in rats through its hypoglycemic, antioxidant, and antiinflammatory mechanisms. J Ocul Pharmacol Ther 2011;27:123-30.

24. Obrosova I, Minchenko A, Marinescu V, Fathallah L, Kennedy A Stockert C, et al. Antioxidants attenuate early up regulation of retinal vascular endothelial growth factor in streptozotocindiabetic rats. Diabetologia 2001;44:1102-10.

25. Cho ML, Jung YO, Moon YM, Min SY, Yoon CH, Lee SH, et al. Interleukin-18 induces the production of vascular endothelial growth factor (VEGF) in rheumatoid arthritis synovial fibroblasts via AP-1-dependent pathways. Immunol Lett 2006;103:159-66.

26. Kim YH, Kim YS, Park SY, Park CH, Choi WS, Cho GJ. CaMKII regulates pericyte loss in the retina of early diabetic mouse. Mol Cell 2011;31:289-93.

27. Mrudula T, Suryanarayana P, Srinivas P, Reddy GB. Effect of curcumin on hyperglycemiainduced vascular endothelial growth factor expression in streptozotocin-induced diabetic rat retina. Biochem Biophys Res Commun 2007;361:528-32.

28. Williams B, Gallacher B, Patel H, Orme C. Glucose-induced protein kinase $\mathrm{C}$ activation regulates vascular permeability factor mRNA expression and peptide production by human vascular smooth muscle cells in vitro. Diabetes 1997;46:1497. 503.

29. Kowluru RA, Tang J, Kern TS. Abnormalities of retinal metabolism in diabetes and experimental galactosemia: VII. Effect of long-term administration of antioxidants on the development of retinopathy. Diabetes 2001;50:1938-42.

30. Zuo ZF, Zhang Q, Liu XZ. Protective effects of curcumin on retinal muller cell in early diabetic rats. Int J Ophthalmol 2013;6:422.

31. Kumar GS, Shetty A, Sambaiah K, Salimath P. Antidiabetic property of fenugreek seed mucilage and spent turmeric in streptozotocin-induced diabetic rats. Nutr Res 2005;25:1021-8.

32. Suryanarayana $P$, Saraswat $M$, Mrudula T, Krishna TP, Krishnaswamy K, Reddy GB. Curcumin and turmeric delay streptozotocin-induced diabetic cataract in rats. Invest Ophthalmol Vis Sci 2005;46:2092-9.

33. Manikandan R, Beulaja M, Thiagarajan R, Priyadarsini A, Saravanan R, Arumugam M. Ameliorative effects of curcumin against renal injuries mediated by inducible nitric oxide synthase and nuclear factor kappa B during gentamicin-induced toxicity in wistar rats. Eur J Pharmacol 2011;670:578-85.

34. Guo C, Li M, Qi X, Lin G, Cui F, Li F, et al. Intranasal delivery of nanomicelle curcumin promotes corneal epithelial wound healing in streptozotocin-induced diabetic mice. Sci Rep 2016;6:29-53. 
35. Shome S, Talukdar AD, Choudhury MD, Bhattacharya MK, Upadhyaya $H$. Curcumin as potential therapeutic natural product: a nanobiotechnological perspective. J Pham Pharmacol 2016;68:1481-500.

36. Li J, Wang P, Ying J, Chen Z, Yu S. Curcumin attenuates retinal vascular leakage by inhibiting calcium/calmodulin-dependent protein kinase II activity in streptozotocin-induced diabete. Cell Physiol Biochem 2016;39:1196-208.

37. Pradhan D, Dasmohapatra T, Tripathy G. Pharmacognostic evaluation of curcumin on diabetic retinopathy in alloxaninduced diabetes through NF-KB and Brn3a related mechanism. Pharmacog J 2018;10:324-32.

38. Gao Y, Zhang Y, Ru YS, Wang XW, Yang JZ, Li CH, et al. Ocular surface changes in type II diabetic patients with proliferative diabetic retinopathy. Int J Ophthalmol 2015;8:358.

39. Zagon IS, Klocek MS, Sassani JW, McLaughlin PJ. Use of topical insulin to normalize corneal epithelial healing in diabetes mellitus. Arch Ophthalmol 2007;125:1082-8.

40. Yates JR, Sepp T, Matharu BK, Khan JC, Thurlby DA, Shahid H, et al. Complement C3 variant and the risk of age-related macular degeneration. N Engl J Med 2007;357:553-61.

41. Osawa T, Kato Y. Protective role of antioxidative food factors in oxidative stress caused by hyperglycemia. Ann N Y Acad Sci 2005;1043:440-51.

42. Sharma S, Chopra K, Kulkarni SK. Effect of insulin and its combination with resveratrol or curcumin in attenuation of diabetic neuropathic pain: participation of nitric oxide and TNF-alpha. Phytother Res 2007;21:278-83.

43. Attia HN, Al-Rasheed NM, Al-Rasheed NM, Maklad YA Ahmed AA, Kenawy SA. Protective effects of combined therapy of gliclazide with curcumin in experimental diabetic neuropathy in rats. Behav Pharmacol 2012;23:153-61.

44. Zhao WC, Zhang B, Liao MJ, Zhang WX, He WY, Wang HB, et al. Curcumin ameliorated diabetic neuropathy partially by inhibition of NADPH oxidase mediating oxidative stress in the spinal cord. Neurosci Lett 2014;560:81-5.

45. Li Y, Zhang Y, Liu DB, Liu HY, Hou WG, Dong YS. Curcumin attenuates diabetic neuropathic pain by downregulating TNF-a in a rat model. Int J Med Sci 2013;10:377-81.

46. Kuhad A, Chopra K. Curcumin attenuates diabetic encephalopathy in rats: behavioral and biochemical evidences. Eur J Pharmacol 2007; 576:34-42.

47. Kumar TP, Antony S, Soman S, Kuruvilla KP, George N, Paulose C. Role of curcumin in the prevention of cholinergic mediated cortical dysfunctions in streptozotocin-induced diabetic rats. Mole Cell Endocrinol 2011;331:1-10.
48. Joshi RP, Negi G, Kumar A, Pawar YB, Munjal B, Bansal AK SNED curcumin formulation leads to enhanced protection from pain and functional deficits associated with diabetic neuropathy: an insight into its mechanism for neuroprotection. Nanomedicine 2013;9:776-85.

49. Ho C, Hsu YC, Lei CC, Mau SC, Shih YH, Lin CL. Curcumin rescues diabetic renal fibrosis by targeting superoxide-mediated Wnt signaling pathways. Am J Med Sci 2016;351:286-95.

50. Hovind P, Tarnow L, Rossing K, Rossing P, Eising S, Larsen N, et al. Decreasing incidence of severe diabetic microangiopathy in type 1 diabetes. Diabetes Care 2003;26:1258-64.

51. Yokoyama H, Okudaira M, Otani T, Sato A, Miura J, Takaike H, et $a l$. Higher incidence of diabetic nephropathy in type 2 than in type 1 diabetes in early-onset diabetes in Japan. Kidney Int 2000;58:302-11.

52. Dronavalli S, Duka I, Bakris GL. The pathogenesis of diabetic nephropathy. Nat Clin Pract Endocrinol Metab 2008;4:444-52.

53. Huang J, Huang K, Lan T, Xie X, Shen X, Liu P, et al. Curcumin ameliorates diabetic nephropathy by inhibiting the activation of the SphK1-S1P signaling pathway. Mol Cell Endocrinol 2013;365:231-40.

54. Tikoo K, Meena RL, Kabra DG, Gaikwad AB. Change in posttranslational modifications of histone $\mathrm{H} 3$, heat-shock protein27 and MAP kinase p38 expression by curcumin in streptozotocin-induced type I diabetic nephropathy. $\mathrm{Br}$ J Pharmacol 2008;153:1225-31.

55. Soetikno V, Sari FR, Veeraveedu PT, Thandavarayan RA, Harima M, Sukumaran V, et al. Curcumin ameliorates macrophage infiltration by inhibiting NF-kB activation and proinflammatory cytokines in streptozotocin induced-diabetic nephropathy. Nutr Metab (Lond) 2011;8:35.

56. Prasad S, Tyagi AK, Bharat B. Recent developments in delivery, bioavailability, absorption and metabolism of curcumin: the golden pigment from golden spice. Cancer Res Treat 2014;46:2-18.

57. Italia JL, Bhatt DK, Bhardwaj V, Tikoo K, Kumar MN. PLGA nanoparticles for oral delivery of cyclosporine: nephrotoxicity and pharmacokinetic studies in comparison to Sand immune Neoral. J Controlled Release 2007;119:197-206.

58. Mittal G, Sahana DK, Bhardwaj V, Ravi Kumar MN. Estradiol loaded PLGA nanoparticles for oral administration: effect of polymer molecular weight and copolymer composition on release behavior in vitro and in vivo. J Controlled Release 2007;119:77-85.

59. Cai K, Qi D, Hou X, Wang O, Chen J, Deng B, et al. MCP-1 upregulates amylin expression in murine pancreatic $\beta$ cells through ERK/JNK-AP1 and NF- $\mathrm{B}$ B related signaling pathways independent of CCR2. PloS one 2011;5:19559. 